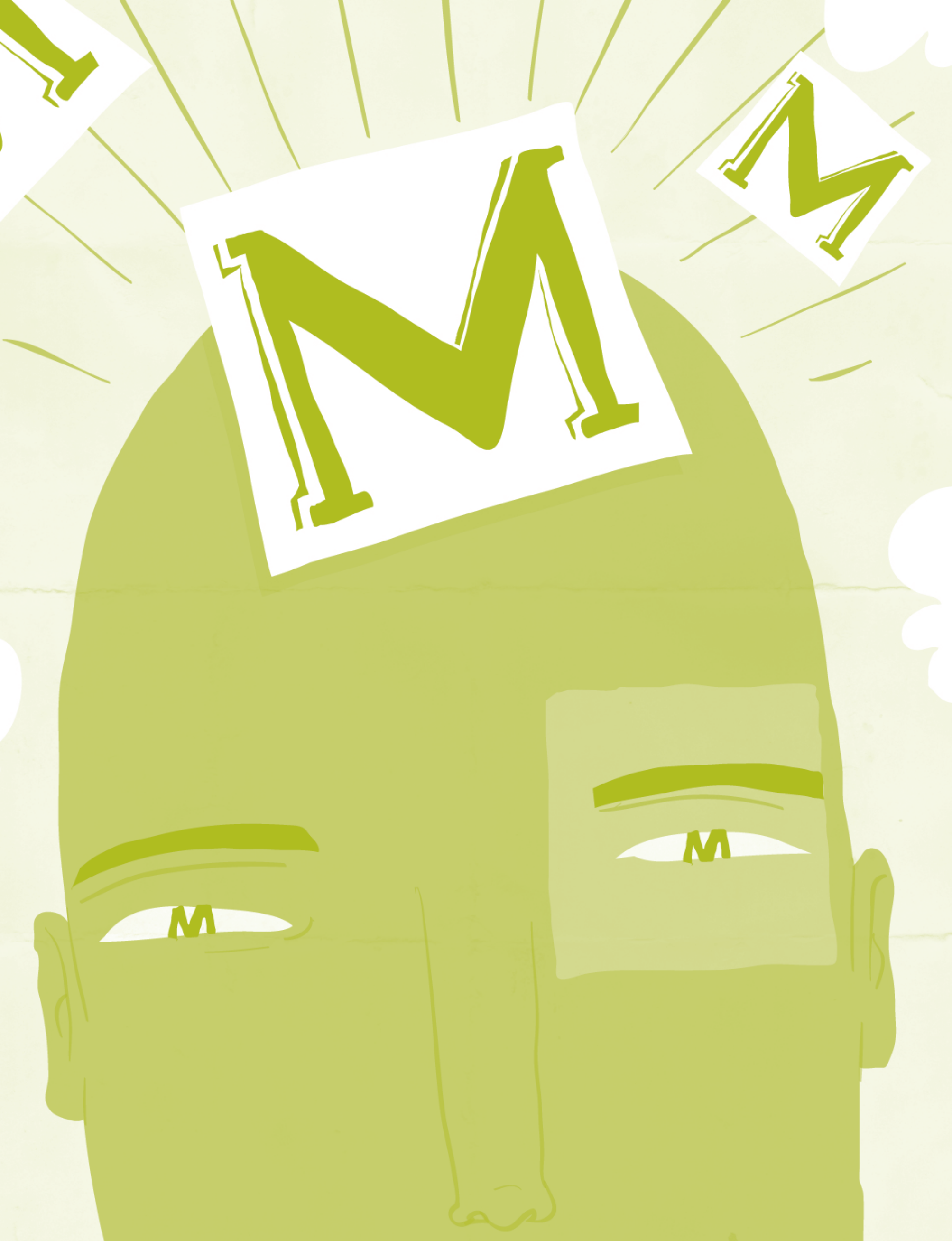




\section{Imagem e reputação na gestão da identidade organizacional}

Luiz Carlos Assis lasbeck

- Doutor em Comunicação e Semiótica pela Pontifícia Universidade Católica de São Paulo (PUC-SP)

- Professor e pesquisador no Curso de Comunicação Social da Universidade Católica de Brasília (UCB)

- Professor de Comunicação Empresarial nos cursos de Turismo, Administração, Marketing e Contabilidade da UPIS - Faculdades Integradas, DF

- Professor de Jornalismo Empresarial e Comunicação Integrada nos cursos de Jornalismo e Cinema do Instituto de Educação Superior de Brasília (IESB)

- Coordenador do MBA Comunicação Organizacional da UPIS - Faculdades Integradas, DF

- Representante do Brasil junto à Federación Latinoamericana de Semiótica (Fels)

- Autor de A arte dos slogans (Annablume: São Paulo, 2002) e dezenas de capítulos de livros de organização, artigos científicos e ensaios, publicados no Brasil e no exterior

- iasbeckk@uol.com.br 


\section{Resumo}

Imagem e reputação são aqui estudadas à vista dos conceitos de discurso e identidade. A gestão da identidade se dá pela compatibilização das intenções do discurso com as impressões interpretantes (imagem). A imagem é estudada como construção mental, fugaz e inconstante, pautada em sensações e afetividades, ao passo que a reputação é entendida e questionada como imagem consolidada, como resposta à impressão causada pelos estímulos discursivos.

PALAVRAS-CHAVE: DISCURSO • IDENTIDADE • IMAGEM • REPUTAÇÃO

\section{Abstract}

Image and reputation are studied here in the light of the concepts of discourse and identity. Identity management is applied through alignment of the intentions of the speech with the impressions made on consumers (image). Image is thus seen as mental construction, which is short-lived and unpredictable, ruled by feelings and affection, while reputation is perceived and questioned as a consolidated image, in response to the impression made by the stimuli of the discourse.

KEYWORDS: DISCOURSE・IDENTITY •IMAGE・REPUTATION

\section{Resumen}

Imagen y reputación se estudian aquí en vista de los conceptos de identidad y discurso. La gestión de la identidad está dada por la aproximación de las intenciones del discurso a las impresiones interpretantes (imagen). La imagen se estudia como una construcción mental, fugaz e inconstante, y se basa en sensaciones y afectividades, mientras que la reputación es la imagen consolidada, una respuesta a la impresión causada por los estímulos discursivos.

PALABRAS CLAVE: DISCURSO •IDENTIDAD •IMAGEN • REPUTACIÓN 
ma das principais dificuldades com que se deparam os pesquisadores e estudiosos da comunicação está ligada à compreensão de conceitos-chave de sua área de trabalho. Além de complexos, e por isso mesmo confusos, alguns conceitos, antes de serem suficientemente elucidados, passam a ser difundidos na prática comunicacional de maneira indiscriminada, sem o necessário cuidado exploratório, proporcionando desvios metodológicos e conclusões inconsistentes em estudos muitas vezes bem encaminhados.

Não pretendemos aqui resolver tal problema, mas levantar a questão em torno de alguns conceitos que têm vigorado na Comunicação Organizacional.

Como a Comunicação é uma ciência eminentemente multidisciplinar, ela herda conceitos originários de outras áreas do conhecimento, dando-lhes feições próprias e contornos coerentes com o corpus epistemológico que a sustenta. Essa migração traz muitos ganhos ao conhecimento, mas pode causar também grandes danos.

Deteremo-nos, neste ensaio, no estudo dos conceitos de imagem, identidade e reputação, essenciais ao estudo da gestão da comunicação nas organizações.

\section{Do discurso à imagem}

Em nossa tese de doutoramento ${ }^{1}$ já levantáramos a questão da identidade como determinante para o entendimento de outros dois conceitos que interagem na sua produção: o discurso e a imagem.

O discurso é um conceito herdado da tradição lingüístico-textual, mais precisamente do estruturalismo e da semiologia européia (GREIMAS et alii, 1967; MAINGUENEAU, 1998; LOZANO et alii, 2002 e DUCROT, 1975). Da produção de estruturas textuais, migrou, ampliando seu espectro para a produção de todo e qualquer conjunto de linguagens que caracterizam a cultura (LOTMAN, 2002) e outras práticas específicas (GREIMAS e COURTÉS, 1982; ORLANDI, 1986), sendo abordado no campo das organizações (SCHWARSTEIN, 1985), das ciências comportamentais (FOUCAULT, 1996), da publicidade (PEREZ TORNERO, 1982), das religiões (JORGE, 1998), da política (ORLANDI, 1983), da psicanálise (LACAN, 1978), entre outros.

1 A administração da identidade - um estudo semiótico da comunicação e da cultura nas organizações, Programa de Estudos Pós-graduados em Comunicação e Semiótica, PUC-SP, 1997. 
Entendemos o discurso como organização e produção de informação em linguagens, com o fim de explicitar e caracterizar intenções, desejos, crenças e conviç̧ões, modos de ser e atuar no mundo, enfim, como um conjunto organizado de textos - na acepção que Lotman (2002) empresta a esse termo - que expressa algo a respeito de quem o produz ou emite.

As contribuições de Mikhail Bakhtin à amplitude do conceito de discurso diversificaram sobremaneira seu espectro. Em sua tese de doutoramento de 1941, sobre a obra de François Rabelais², Bakhtin desenvolveu o conceito do que ele denominou "dialogismo", evidenciando que todo discurso embute em si mesmo a pressuposição de um possível discurso do interlocutor (e da cultura) que com ele interage. Dessa forma, não há como considerarmos o discurso isoladamente do público ao qual se destina, do receptor e do ambiente do qual emergem esses "textos organizados e com função" (LOTMAN, 2002).

Levados ao campo da recepção, identificamos - ainda em nossa tese de doutoramento (IASBECK, 1997) - a emergência daquilo que denominamos "imagem", ou seja, a configuração mental e sobretudo afetiva que o receptor elabora com base na relação do discurso que recebe e suas próprias idiossincrasias, experiências anteriores, visões de mundo, desejos e necessidades.

Para delimitarmos o conceito de "imagem", apoiamo-nos na obra fundamental do norte-americano W. J. T. Mitchell, Iconology: image, text, ideology, publicada inicialmente em 1986 pela The University of Chicago Press. Já no primeiro capítulo (What is a image?), Mitchell nos mostra as fronteiras existentes entre aquilo que denomina "família de imagens", relacionando as competências de significação desse conceito em diversas possibilidades de aplicação. Ele nos fala das imagens gráficas - impressas e esculpidas, a exemplo das pinturas, estátuas e designs -; das imagens ópticas - de projeção e espelhadas -; das imagens perceptuais - captadas pelos órgãos dos sentidos, a aparência das coisas, as espécies etc. -; das imagens verbais - advindas das metáforas, descrições e narrações literárias - e, enfim, das imagens mentais - formadas pelos sonhos, pela memória, pelas idéias, fantasias e fantasmas.

Embora tal classificação nos pareça rígida e despregada da realidade - sempre um emaranhado dessas possibilidades -, Mitchell tem o mérito de nos situar textualmente no campo da observação e da ponderação científica que pretendemos ao nos referirmos ao material resultante da interpretação do discurso recebido num ato de comunicação qualquer e, aqui especificamente, no contexto do discurso organizacional.

Ao optarmos por classificar como "imagem mental" aquela formada pelo consumidor à vista dos anúncios publicitários, da sua experiência pessoal de atendimento nu-

2 A cultura popular na idade média e no renascimento. Hucitec: São Paulo, 1993. 


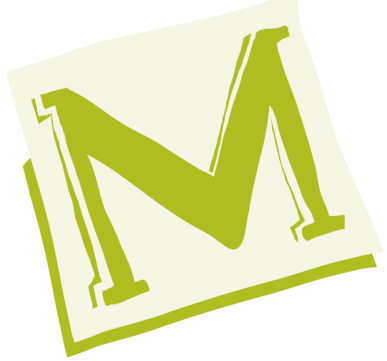

ma empresa, num determinado tempo e lugar, dos diversos estímulos visuais, acústicos, olfativos, táteis e - dependendo do caso - gustativos de um mesmo emissor, estamos também assumindo a complexidade de tal formulação no que concerne à imbricação desses estímulos na mente do receptor.

Dessa forma, recorremos à Teoria Geral do Signo, de Charles Sanders Peirce ${ }^{3}$, para caracterizar as nuances significativas da imagem mental para aquele que a produz. Após analisarmos as possibilidades icônicas, indiciais e simbólicas da imagem mental produzida pelos discursos organizacionais, localizamos no campo do ícone a mais forte de todas as "impressões". Ou seja, a impressão causada pelos discursos organizacionais na mente de quem os recebe tende a ser fortemente icônica e, portanto, eivada de emoções, humores, sensações, qualidades estéticas e afetivas. Isso não quer dizer que a imagem não indica ou simboliza, mas que todos os demais atributos advêm da competência afetiva. Por esse motivo, a imagem das organizações na mente dos seus diversos públicos (e também na mente daqueles que a integram) tende a ser fugaz, efêmera, vulnerável a alterações de toda ordem (humores, condições de tempo, ambientes e contextos, relações extratextuais etc.).

Evidentemente, aferir uma "imagem" tão inconstante e instável, além de ser temerário, pode ser mesmo uma atitude organizacionalmente irresponsável, uma vez que pesquisas dessa monta têm elevado custo e resultam em informações pouco úteis para os formuladores do discurso. Urgia, pois, buscarmos novas alternativas, produtivamente viáveis, de aferir a qualidade da imagem, de modo a subsidiar as reformulações do discurso. Ainda que não nos ocorram formas de deter a imagem, entendemos que toda pesquisa nessa direção deveria contemplar a instabilidade dos seus resultados. Portanto, as pesquisas deveriam ser constantes - e não apenas sazonais -, de forma a contemplar as oscilações da qualidade da imagem no tempo e no espaço.

\section{A aferição da imagem pela satisfação: uma experiência}

No período de 1998 a 2001, testamos no Banco do Brasil uma pesquisa de satisfação do cliente que buscava tão-somente aferir a qualidade de sensação provocada pelo discurso da empresa nos seus diversos públicos. Disponibilizada de forma randômica nos terminais de atendimento informatizado da empresa, de vasta capilaridade no território nacional, a pesquisa aferia a satisfação do cliente no momento de sua manifestação. Ao mesmo tempo, todos os dados registrados eram agregados em sistemas informatizados que os categorizavam e transformavam em pontuação os resultados

3 In: SANTAELLA, Lúcia. A teoria geral dos signos: semiose e autogeração. São Paulo: Ed. Ática, 1995. p. 83-108. 
obtidos, fornecendo, assim, à empresa, em tempo real, os dados de que ela necessitava para repensar seu discurso e localizar eventuais problemas de comunicação.

Por ter caráter eminentemente icônico (sentimental, afetivo), a pesquisa de satisfação retratava oscilações muito significativas no tempo, o que nos levava a identificar os momentos de variação com a produção e transmissão dos textos que constituíam o discurso empresarial. Dessa forma - e apenas aproximadamente - conseguíamos elaborar quadros referenciais de feedback com alto grau de confiabilidade (uma vez que partiam dos próprios usuários) e de baixíssimo custo operacional (já que nos servíamos de um sistema de capilaridade já existente para o auto-atendimento).

Se dessa forma obtínhamos resultados aparentemente objetivos sobre questões tão subjetivas quanto a satisfação do cliente, de outra forma não tínhamos condições de precisar os caminhos que deveriam ser seguidos para minorar os problemas e otimizar a qualidade do atendimento. A necessidade de buscar sugestões e localizar com maior precisão os pontos de estrangulamento que determinavam baixa satisfação (ou mesmo insatisfação) levou-nos a explorar a imagem sobre outras bases. No caso, sobre fundamentos simbólicos, mais consistentes e duradouros, ainda que também mutáveis e sujeitos à instabilidade.

\section{Da imagem à reputação}

Convencidos de que seria necessário obter maior regularidade na captação das impressões ou imagens mentais, buscamos desenvolver nossas pesquisas em torno do conceito de identidade, uma vez que nomeáramos o processo de reformulação do discurso via dados da imagem como um processo de "Administração da Identidade".

Cabe aqui, resumidamente, esclarecer que fundamentamos o estudo de tal processo nos conceitos de identidade desenvolvidos desde Aristóteles ${ }^{4}$, passando pela teoria matemática de Leibniz, as teorias psicológicas do caráter e da personalidade (CLAPIERVALADON, 1988), as teorias relacionais de F. Waismann, da Escola de Viena (ABBAGNANO, 1986) e também as teorias sociológicas que trabalham a relações entre indivíduos e organizações (CIAMPA, 1989, ETKIN e SCHWARSTEIN, 1995).

Optamos pela possibilidade de conceituarmos identidade como o resultado da relação produtiva entre discurso e imagem, ou seja, o que surge de afinidade entre as intenções do discurso e as impressões do receptor. Essa "afinidade" não se dá apenas por congruências, mas também pelas diferenças geradas e esperadas por ambos os lados da relação. Para tanto, o conceito de identidade de F. Waismann pareceu-nos mais adequado porque operativo para nossos propósitos de pesquisa.

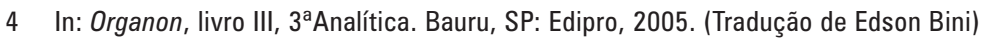


Assim, "identidade" é um conceito que surge da relação entre o emissor do discurso e o receptor desses estímulos. E administrá-la corresponde a coordenar a produção, a reprodução e a reformulação do discurso à vista dos dados obtidos pela pesquisa de imagem.

Instável, como nos parecia (e aparecia), a imagem mental (MITCHELL, 1986) não proporcionava dados seguros para a promoção de uma gestão efetiva da identidade organizacional.

É nesse sentido e nessa oportunidade que o conceito de reputação emerge para trazer novas possibilidades exploratórias à administração da identidade. A reputação estaria relacionada à "opinião" dos outros (FLYNN, 2007), assim como a imagem está relacionada à "satisfação" dos outros? É o que discutiremos a seguir.

\section{Reputação e metodologia de pesquisa}

É bastante comum, na prática mercadológica, associar a imagem de um produto, de uma marca ou de uma empresa ao conjunto das opiniões que um determinado público - normalmente o público-alvo -, expressa em pesquisas de caráter quantitativo e qualitativo.

A imagem mental a que nos referíamos é formada, em grande parte, com contribuições do imaginário do público, que se agregam aos estímulos recebidos de forma nem sempre previsível e administrável. Assim, quando nos referimos à "imagem", falamos do produto dinâmico da elaboração mental (imaginação) de quem mantém com o objeto de sua percepção e experiência uma relação comunicativa. Nessa relação, o objeto da percepção se mescla com os dados do imaginário do percebedor e o resultado poderia ser a impressão causada nessa mente interpretante. Poderíamos simplesmente denominá-la "impressão".

Quando alguns pesquisadores - sobretudo da área do marketing - optam por utilizar o termo "reputação", não estão apenas substituindo terminologicamente a mesma idéia, mas alterando substancialmente significados que fazem muita diferença: enquanto a "imagem", como vimos, se forma na mente do receptor com base em estímulos mais densamente povoados por sensações e qualidades (IASBECK, 1998, p. 173-192 e COSTA, 1999, p. 59-62), a reputação é formada por juízos de caráter lógico e alicerçada em argumentos, opiniões e até mesmo conviç̧ões, crenças consolidadas (JABLIN, 2001, p. 754-756 e FLYNN, 2007).

Dados estatísticos obtidos por meio de uma grande variedade de metodologias inquisitórias têm sido normalmente aceitos como válidos pelas organizações para determinar a performance comercial de produtos e serviços, não obstante as distorções e 
IMAGEM E REPUTAÇÃO NA GESTÃO DA IDENTIDADE ORGANIZACIONAL • LUIZ CARLOS ASSIS IASBECK

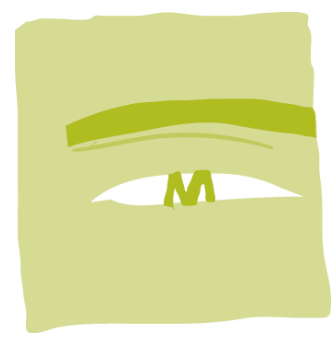

distanciamentos que tais modelos propiciam (BESSON, 1995, p. 25-73). E mais: conferem caráter pretensamente científico - e, portanto, objetivo - às informações obtidas, diluindo a desconfiança na relatividade das opiniões subjetivas do público.

Hoje, institutos de pesquisa de comunicação e organizações interessadas em conhecer seus clientes demandam metodologias capazes de detectar desde os sonhos do consumidor até suas mais prementes necessidades do dia-a-dia (PINHEIRO et alii, 2006, p. 63-73). As informações que apuram por amostragem precisam ser configuradas como "espelhos da realidade" para convencerem os produtores do discurso. Geralmente, o que se promove nessas pesquisas são manobras técnicas de afunilamento das diferenças subjetivas em favor da pasteurização dos dados obtidos em torno de um ou mais elementos considerados "universais" ou "invariantes". As conclusões assim obtidas podem aparecer também vinculadas a imagens, textos ou até mesmo sons (BAUER e GASKELL, 2002, p. 15-17), em relações associativas sensoriais ou sinestésicas.

Por isso, convencem. Fornecem os contornos de uma possível "imagem real" do objeto pesquisado, mas, por não levarem em conta a inconstância das informações ${ }^{5}$, não expressam necessariamente uma imagem, muito menos uma reputação.

A “opinião" assim aferida, além de manipulada, é manipuladora, pois compreende e faz compreender, age e faz agir, metaboliza e faz transformar seu objeto, deixando definitivamente a passividade que lhe conferem as mais ingênuas teorias do how to ma$k e$, que algumas correntes do marketing e da administração de empresas elegeram como balizadoras da boa performance (ETKIN e SCHVARSTEIN, 1995, p. 5-10).

O que nos interessa nesta reflexão é questionar não as escolhas metodológicas dos institutos de pesquisa ou a ingenuidade dos consumidores de informações simplificadas, mas o entendimento e o consentimento tácito daquilo que se denomina "opinião pública" na formação da reputação das organizações.

\section{Reputação e opinião}

Para tanto, valemo-nos do ensaio A opinião pública e seus porta-vozes, do semioticista Eric Landowski ${ }^{6}$, no qual são discutidas questões que relativizam a pretensa cientificidade dessa modalidade de opinião coletiva.

5 ..."as escolhas carecem de permanência e consistência nos hábitos dos entrevistados"... (SHET, MITTAI e NEWMAN, 2001, p. 473-475).

6 In: A sociedade refletida. São Paulo: Educ-Pontes, 1992. p. 19-43. 
Segundo Landowski, há dois tipos de especialistas em opinião pública: “Uns interrogam-se sobre o seu modo de existência e sobre as condições de sua manifestação, outros respondem por sua existência e se encarregam, por profissão, de manifestá-la" (1992, p. 27).

A precisão e o rigor científicos - características que imprimem credibilidade aos resultados das pesquisas - são, porém, a grande preocupação de uns e outros: enquanto os profissionais dos institutos de opinião enquadram dados em modelos matemáticos e estatísticos, os estudiosos das ciências sociais e da semiótica da cultura investigam o modo de formação e de transformação dessa opinião, procurando detectar a pluralidade de fatores que interferem na sua dinâmica.

Landowski adverte que, como "fenômeno que subsume a pluralidade das opiniões singulares” (1992, p. 19), a opinião pública pode manifestar-se também - e muito comumente - por profissionais que mantêm estreito contato com o público, tais como os jornalistas e os políticos. O "misterioso sentido inato de opinião pública" (LANDOVSKI, 1992, p. 19) que manifestam apóia-se em práticas que concebem a opinião como "uma espécie de pessoa"7. Os homens de propaganda e marketing, assim como os jornalistas, funcionam como porta-vozes de um público que não lhes legitimou representatividade, mas que é susceptível de ser manipulado pelas práticas da provocação, da intimidação, da tentação e da sedução, artifícios narrativos tão utilizados pela propaganda e pelos órgãos de imprensa em matérias interpretativas e opinativas.

Estaria, dessa forma, a "reputação" de uma organização marcada e manipulada pelos próprios instrumentos que buscam captá-la por meio de pesquisas? Haveria, então, duas imagens distintas, uma imagem captada pelas pesquisas e outra produzida na mente dos consumidores e inacessível, pelos parâmetros da cientificidade, às metodologias conhecidas?

Antes de buscar resposta a essas perguntas, é preciso assumir que a opinião pública precisa existir para que por ela se pautem as análises da eficiência e da efetividade dos discursos; é ela que explica, justifica e fundamenta a reputação; a maioria dos problemas que dificultam sua deteç̧ão está relacionada, segundo Landowski, à "multiplicidade das acepções... de que os sociólogos foram os primeiros a tomar consciência" (1992, p. 20).

Para distinguir duas categorias importantes de opinião pública - a do público e a dos intérpretes do sentimento público -, Landowski reporta-se à organização do teatro grego antigo, no qual havia o palco (logeion), local em que se desenvolvia a cena, e a orquestra, de onde o coro observava a cena e a comentava para o público nas arquibancadas da platéia (koilon). A reação do público era observada e provocada, em mui-

7 Expressão usada por Ferdinand Brunot, historiador da língua francesa, citado por Landowski (1992). 
tos momentos, pelos integrantes do coro, que cumpriam dupla função: a de interpretar as cenas para o público e a de instigar os protagonistas da peça no sentido das expectativas desse mesmo público.

Nesse caso, fica visível a existência de instâncias intermediárias entre a opinião coletiva e o destinatário final dessa opinião, o destinador-ator. As transformações e rearrumações de caráter afetivo, lógico e argumental por que passam as reações percebidas da platéia ensejam o surgimento de uma meta-opinião que pode, ou não, corresponder - em diferentes níveis e graus - ao sentimento do público.

\section{A mídia e a formação da reputação}

É possível perceber, assim, que o grande público - tanto do teatro grego quanto das empresas e de seus produtos - produz suas próprias imagens e opiniões (reputações) em sistema de intermediação. Tudo nos leva a crer que na sociedade moderna, comercial e capitalista, são os discursos da mídia os grandes "formadores de opinião", ao congregarem também os discursos de líderes comunitários e sindicais, de políticos, empresários, intelectuais, artistas e outros. Assim representado, o consumidor, os fornecedores, enfim todos os públicos de interesse de uma organização tendem a afunilar suas perspectivas para um discurso unificador e midiático que os estratifica à medida que, paradoxalmente, os massifica.

Os esforços para segmentar a clientela (KOTLER, 2000, p. 277-301) não constituem, dessa forma, senão a manifestação de um desejo de especificar características que serão, num segundo momento, pasteurizadas para significarem os mesmos elementos estruturais invariantes que caracterizavam a grande massa disforme de públicos de interesse.

Voltamos, portanto, ao ponto de partida, com um agravante: o crescente avanço das tecnologias de informação tende a diminuir ainda mais o tempo de recepção e resposta aos estímulos discursivos, evidenciando a dinâmica interativa entre destinador e destinatário e a premência da implementação de meios estáveis e altamente flexíveis para a reciclagem do discurso (IASBECK, 1997, p. 45).

Porque os contornos da imagem pública de uma empresa oscilam a todo momento, as pesquisas e sondagens de caráter científico (matemático e estatístico) que congelam - à maneira de uma fotografia - um instante possível e limitado da percepção não devem ser entendidas como definitivas e consideradas como absolutamente válidas, espelhos da realidade na qual se pretende atuar, num espectro de tempo maior do que o momento em que foi limitadamente produzida. Em outras palavras, a imagem instável não pode ser consumida como uma perene reputação. 
IMAGEM E REPUTAÇÃO NA GESTÃO DA IDENTIDADE ORGANIZACIONAL • LUIZ CARLOS ASSIS IASBECK

\section{A captação da reputação pela filtragem da mediação}

A criação de meios permanentes e monitoráveis de resposta imediata do público seja por meio de comentários e sugestões, seja por críticas e reclamações - afigurase como procedimento desejável para um mapeamento indefinivelmente provisório dos contornos da imagem pública da empresa, via análise dos dados obtidos, podendo, dessa forma, fornecerem subsídios para a formação de uma reputação sustentável.

$\mathrm{Na}$ análise dos dados assim obtidos, os resultados do contato direto e aparentemente desintermediado com o público - que se expressa voluntariamente - devem ser somados aos esforços de leitura das interpretações midiáticas, disponíveis nos jornais, revistas, programas de TV, eventos de massa, dentre outros, e ao contato direto com aquele público privilegiado, os "formadores de opinião".

Tal confrontação pode gerar uma conformação? É possível, desde que os dados mais estáveis (da reputação) estejam permeando aqueles mais fugazes e indefiníveis (da imagem). E essa é uma hipótese que ainda precisa ser demonstrada por instrumentos tentativos de aferição da imagem. E se comprovada, os subsídios a serem gerados para a reciclagem do discurso (IASBECK, 1997, p. 197) tenderão a ser mais substanciosos, menos onerosos e mais facilmente operacionalizáveis por estratégias de comunicação.

Assim seria possível minimizar o alto risco de se investir na mensuração e no delineamento dos contornos da imagem com base em "invariantes" e "universais", técnica comumente adotada pelos institutos de opinião. Estaria afastada também a possibilidade de se produzir, ao final, resultados tecnicamente previsíveis, muito próximos às "certezas do senso inato de opinião", como diz Landowski.

\section{A reputação, as razões do público, os interesses das organizações}

Um conhecido ditado popular afirma que, nas relações comerciais, "o cliente tem sempre razão". Os resultados desta pesquisa pautada pela filtragem da mediação, como aqui proposta, poderão inverter a aparente ditadura da reputação do receptor sobre as intenções estratégicas do emissor, sugerindo uma parceria de interesses em torno de desafios comuns.

A relevância de se criar e se manter instrumentos eficazes de aferição da imagem e da reputação se justifica pelo fato de ser esta a condição essencial para que uma organização - seja pública, seja privada - possa dispor de mecanismos eficazes de administração de sua identidade (IASBECK, 1998). Uma imagem favorável ou desfavorável não tem, evidentemente, um fim em si mesma. Ela se torna imprescindível, porém, no processo dinâmico de gestão da identidade, cuja finalidade - nas atividades comerciais 
- é obter o maior grau possível de adesão e empatia por parte dos diversos públicos de interesse.

Por isso, nas práticas comerciais busca-se primordialmente alargar os espaços da identidade, que podem ser traduzidos por graus incertos e não totalmente previsíveis de afinidade entre produção e recepção, entre os interesses, desejos e necessidades de quem produz e os interesses, desejos e necessidades de quem consome.

Esse "incerto" grau - ainda que nunca líquido e certo - precisa ser ocupado proativamente pelo discurso das organizações; deve estar presente em suas preocupações estratégicas e constituir um espaço virtual de experimentações. Ainda que jamais possa ser abolido, pode - se administrado - fornecer elementos necessários para transformar espontaneamente imagens em reputação e reputação em novas imagens, criando um ciclo renovável de expectativas duradouras e satisfações provisórias.

É nesse contexto que o conhecimento operativo da imagem e da reputação pode otimizar os recursos de comunicação de uma organização, tornando-a competente e competitiva num mercado pleno de possibilidades e tão carente de soluções inovadoras.

\section{Referências}

ABBagnanO, N. Dicionário de filosofia. México: Fondo de Cultura Económica, 1986.

ARISTÓTELES. Órganon. Bauru, SP: Edipro, 2005. (Texto integral. Tradução de Edson Bini).

BAKHTIN, Mikhail. A cultura popular na idade média e no renascimento - o contexto de François Rabelais. São Paulo: Editora Hucitec, 1993.

BARROS, D. L. P. Teoria semiótica do texto. São Paulo: Ática, 1990.

BAUER, Martins W. e GASKELL, George (ed). Pesquisa qualitativa com texto, imagem e som. Petrópolis: Vozes, 2002.

BESSON, Jean-Louis (org.). A ilusão das estatísticas. São Paulo: Editora Unesp, 1995.

CIAMPA, A. Identidade. In: LANE, Sylvia e CODO, Wanderlei (orgs). Psicologia social: o homem em movimento. São Paulo: Brasiliense, 1989.

COSTA, Joan. Imagen corporativa en el siglo XXI. Buenos Aires: La Crujía Ediciones, 2001.

DUCROT, Oswald. Estruturalismo e lingüística. São Paulo: Cultrix, 1975.

ETKIN, Jorge e SCHVARSTEIN, Leonardo. Identidad de las organizaciones - invariancia y cambio. Buenos Aires, Barcelona y México: Paidos, 1995.

FIORIN, J. L. Elementos de análise do discurso. São Paulo: Contexto-Edusp, 1989. 
FLYNN, Terry. Corporate reputation management and branding. Curso de Especialização Comunicação Empresarial - Syracuse University 12/4/2007. In: GARCIA, Aislan et alii. A cultura organizacional como alicerce da reputação corporativa. Texto apresentado no I Sembrarp. Salvador, outubro de 2007.

FOUCAULT, Michel. A ordem do discurso. São Paulo: Loyola, 1996.

GREIMAS, A. J. e COURTÉS, J. Dicionário de semiótica. São Paulo: Cultrix, 1985.

GREIMAS et alii. Lingüística y comunicación. Buenos Aires: Ediciones Nueva Visión, 1967.

IASBECK, L. C. A. A administração da identidade: um estudo semiótico da comunicação e da cultura nas organizações. Tese (Doutorado) - Programa de Pós-Graduação em Comunicação e Semiótica. São Paulo: PUC-SP, 1997.

JABLIN, Fredric. Organizational entry, assimilation and disengagement/exit. In: JABLIN and PUTNAM (orgs). The new handbook of organizational communication. Thousand Oaks, London and New Delhi: Sage Publications Inc., 2001.

KOTLER, P. Administração do marketing. São Paulo: Pearson Hall, 2000.

LACAN, J. Escritos. São Paulo: Perspectiva, 1978.

LANDOWSKI, E. A. Sociedade refletida. Campinas, SP: Educ-Pontes, 1992.

LOZANO, Jorge et alii. Análise do discurso: por uma semiótica da interação textual. São Paulo: Littera Mundi, 2002.

LOTMAN, I. M. et alii. Teses para uma análise semiótica da cultura. In: MACHADO, I. Escola de semiótica. São Paulo: Ateliê Editorial, 2003, p. 99-134.

MAINGUENEAU, Dominique. Termos-chave da análise do discurso. Belo Horizonte: Editora UFMG, 2000.

MITCHELL, W. J. T. Iconology: image, text, ideology. Chicago and London: The University of Chicago Press, 1986.

ORLANDI, E. P. Análise do discurso: algumas observações. São Paulo: Delta, 1986.

ORLANDI, E. O. Discurso e leitura. São Paulo: Cortez, 1993.

PINHEIRO et alii. Comportamento do consumidor e pesquisa de mercado. Rio de Janeiro: FGV Editora, 2006.

SANTAELLA, Lúcia. A teoria geral do signo: semiose e autogeração. Ática: São Paulo, 1995.

SCHVARSTEIN, Leonardo. Psicología social de las organizaciones. Buenos Aires, Barcelona y México: Paidos, 1995.

SHET, J. N.; MITTAL, B.; NEWMAN, B.I. Comportamento do cliente - indo além do comportamento do consumidor. São Paulo: Atlas, 2001.

SIMÕES, Jorge. Cultura religiosa: o homem e o fenômeno religioso. São Paulo: Loyola, 1998.

TORNERO, J. M. P. Semiótica de la publicidad. Barcelona: Editorial Mitre, 1982.

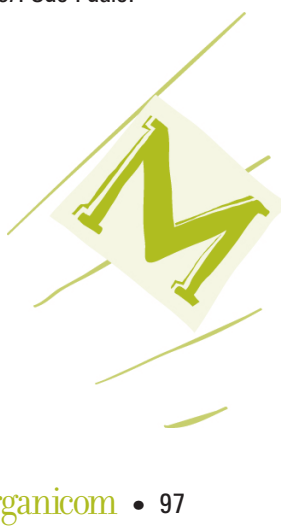

